\title{
Balance between Transmitter Availability and Dopamine D2 Receptors in Prefrontal Cortex Influences Memory Functioning
}

Goran Papenberg ${ }^{1, *}$, Nina Karalija 2,3, Alireza Salami@1,3,4, Anna Rieckmann ${ }^{3}$, Micael Andersson ${ }^{2,3}$, Jan Axelsson ${ }^{2,3}$, Katrine Riklund ${ }^{2,3}$, Ulman Lindenberger ${ }^{5,6}$, Martin Lövdén ${ }^{1}$, Lars Nyberg ${ }^{2,3,7}$ and Lars Bäckman ${ }^{1}$

${ }^{1}$ Aging Research Center, Karolinska Institute and Stockholm University, S-17177 Stockholm, Sweden 2Department of Radiation Sciences, Umeå University, S-90187 Umeå, Sweden ${ }^{3}$ Umeå Center for Functional Brain Imaging (UFBI), Umeå University, S-90187 Umeå, Sweden ${ }^{4}$ Wallenberg Centre for Molecular Medicine, Umeå University, S-90187 Umeå, Sweden ${ }^{5}$ Center for Lifespan Psychology, Max Planck Institute for Human Development, D-14195 Berlin, Germany ${ }^{6}$ Max Planck UCL Centre for Computational Psychiatry and Ageing Research, D-14195 Berlin, Germany and UK-WC1B 5EH London, UK and ${ }^{7}$ Department of Integrative Medical Biology, Umeå University, S-90187 Umeå, Sweden

Address correspondence to Goran Papenberg, Aging Research Center, Karolinska Institutet, Tomtebodavägen 18 A, 17177 Stockholm, Sweden. Email: goran.papenberg@ki.se

\begin{abstract}
Insufficient or excessive dopaminergic tone impairs cognitive performance. We examine whether the balance between transmitter availability and dopamine (DA) D2 receptors (D2DRs) is important for successful memory performance in a large sample of adults ( $n=175,64-68$ years). The Catechol-O-Methyltransferase polymorphism served as genetic proxy for endogenous prefrontal DA availability, and D2DRs in dorsolateral prefrontal cortex (dlPFC) were measured with $\left[{ }^{11} \mathrm{C}\right]$ raclopride-PET. Individuals for whom D2DR status matched DA availability showed higher levels of episodic and working-memory performance than individuals with insufficient or excessive DA availability relative to the number of receptors. A similar pattern restricted to episodic memory was observed for D2DRs in caudate. Functional magnetic resonance imaging data acquired during working-memory performance confirmed the importance of a balanced DA system for load-dependent brain activity in dIPFC. Our data suggest that the inverted-U-shaped function relating DA signaling to cognition is modulated by a dynamic association between DA availability and receptor status.
\end{abstract}

Key words: $\left[{ }^{11} \mathrm{C}\right]$ raclopride, catechol-O-methyltransferase, dopamine D2 receptors, episodic memory, working memory

\section{Introduction}

The dopamine (DA) system contributes to higher-order cognitive functions, such as working memory (Kimberg et al. 1997; Liggins 2009; Williams and Goldman-Rakic 1995). Animal work suggests that maintenance of representations in working memory is related to the prefrontal DA D1 receptor system (Sawaguchi 2001; Wang et al. 2004). Likewise, mice deficient for DA D2 receptors (D2DRs) exhibit spatial working-memory deficits (Glickstein et al. 2002). D2DRs also have a role in phasic working-memory oper- 
ations, relevant for updating the contents of working memory (D'Esposito and Postle 2015; O'Reilly 2006; Bäckman et al. 2011). Specifically, blocking D2DRs in prefrontal cortex (PFC) impairs both learning of new stimulus-response associations and cognitive flexibility (Puig et al. 2014). This is in line with the dualstate theory of prefrontal DA function (Durstewitz \& Seamans, 2008), which suggests the existence of two discrete dynamic regimes. The D1 receptor-dominated state is associated with robust online maintenance of information and the $\mathrm{D} 2$ receptordominated state is beneficial for flexible and fast switching among representational states.

In humans, DA-relevant genes have been found to modulate working-memory performance. For instance, the catecholO-methyltransferase (COMT) Val158Met polymorphism gives rise to individual differences in extracellular degradation of DA in PFC. COMT Val homozygotes have 3-4-fold higher DA-degrading activity than Met homozygotes (Lotta et al. 1995), resulting in less prefrontal DA availability and typically lower working memory (Witte and Floel 2012), as well as reduced episodic memory (Wimber et al. 2011; de Frias et al. 2004).

However, high endogenous DA levels or D2DR availability are not always beneficial to cognitive functioning. Recently, we showed that a subgroup of individuals with high striatal and extrastriatal D2DRs availability exhibits particularly poor episodic and working memory, whereas there was a positive relationship between D2DRs and memory performance for most individuals (Lövdén et al. 2018). Concerning DA signaling and cognitive functioning, there is evidence for an inverted-U-shaped dose-response curve. This model holds that excessively low as well as excessively high DA tone is associated with reduced performance (Cools and D'Esposito 2011). As an example of detrimental effects from excessive DA signaling, administration of a D2DR agonist in nonhuman primates impairs working memory and induces "hallucinatorylike" behaviors (Arnsten et al. 1995). Cognitive disturbances via D2DR stimulation could arise from molecular cascades through which levels of noise in prefrontal circuits might increase (Gee et al. 2012). An optimal balance would reflect equilibrium between transmitter availability and receptor status. PET studies in healthy adults showed that pre- and postsynaptic DA markers may not necessarily be correlated. Although DA synthesis capacity correlated with D2DR binding, there was no association with actual DA release (Berry et al. 2018). A negative relationship was also found between endogenous DA synthesis rate and D2DR availability (Ito et al. 2011). On this foundation, we hypothesize that the balance between DA availability and D2DR status is important for optimal neurotransmission and, consequently, cognitive performance.

Prefrontal D2DR availability was assessed via $\left[{ }^{11} \mathrm{C}\right]$ raclopride binding potential $\left(\mathrm{BP}_{\mathrm{ND}}\right)$ determined in positron emission tomography (PET) assessments, and a genetic variation in the COMT gene served as a proxy for endogenous prefrontal DA tone $(\mathrm{Met} / \mathrm{Met}>\mathrm{Met} / \mathrm{Val}>\mathrm{Val} / \mathrm{Val})$. In the following, we also refer to these genetically inferred differences as differences in DA availability. It is well known that $\left[{ }^{11} \mathrm{C}\right]$ raclopride $\mathrm{BP}_{\mathrm{ND}}$ is sensitive to endogenous DA levels (Laruelle 2000). Importantly, similar mean $\mathrm{BP}_{\mathrm{ND}}$ values and dispersions of values around the mean [standard deviation (SD)/mean] were found across allelic groups for the regions of interest in our study. Another PET study demonstrated similar levels of raclopride $\mathrm{BP}_{\mathrm{ND}}$, density, and ligand affinity among COMT groups (Hirvonen et al. 2010). These observations, and particularly the existence of similar ranges

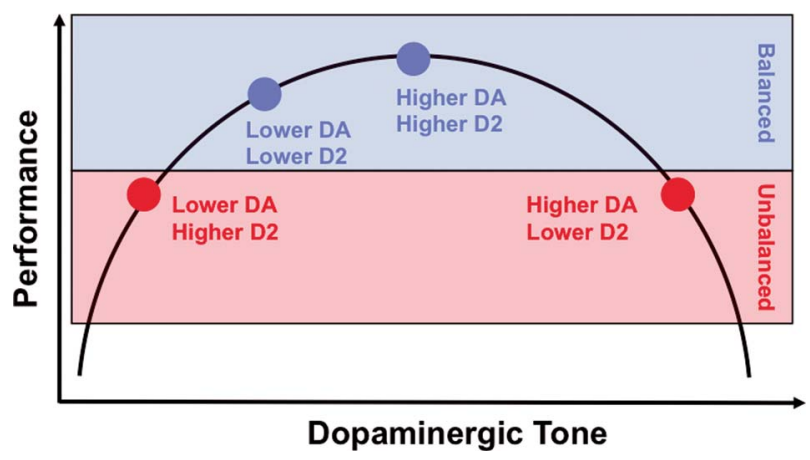

Figure 1. Hypothesized modulation of the inverted-U-shaped function relating DA signaling to cognition by DA availability and receptor status.

of inter-individual differences in $\left[{ }^{11} \mathrm{C}\right]$ raclopride $\mathrm{BP}_{\mathrm{ND}}$ among the allelic groups in our study, indicate that BP estimations are not biased across COMT groups (see Supplementary Table A1). D2DRs are also expressed to a minor extent in the presynaptic neuron, serving as autoreceptors (Mottola et al. 2002; Ford 2014). However, given this low expression, our measures of D2DR availability should mainly reflect postsynaptic receptors.

If balance between DA receptors and availability is important, we expected to find better working- and episodic-memory performance among individuals with well-balanced prefrontal DA availability and D2DRs, with higher dopaminergic tone resulting in better performance. Individuals with low endogenous DA levels (Val/Val) and high D2DR status would perform worse, likely reflecting low DA activity for signal transmission. Similarly, high endogenous DA tone (Met/Met) in combination with low D2DR status should be associated with lower cognitive performance, due to excessive DA relative to the number of receptors (Fig. 1). Alternatively, the highest and lowest availability with respect to both D2DR status and transmitter availability may be associated with the worst performance, because these individuals are the most removed from the apex of the inverted-U-shaped function. Such a pattern would speak against the balance hypothesis.

We focus on the dorsolateral PFC (dlPFC) given its importance for working (Eriksson et al. 2015) and episodic memory (Kapur et al. 1995; Shallice et al. 1994). For comparative purposes, the same analyses were conducted with D2DR availability in caudate, which is also implicated in episodic (e.g., Nyberg et al. 2016) and working memory (e.g., Bäckman et al. 2011). COMT is abundantly expressed in PFC and considerably less so in striatum (Matsumoto et al. 2003). Thus, we expected relatively weaker effects involving the caudate.

Finally, we use functional magnetic resonance imaging (fMRI) data to investigate whether individuals with balanced and imbalanced DA systems in dlPFC differ in brain activation during a working-memory task. Working memory load potentiates release of endogenous DA (Jacobs and D'Esposito 2011). Individuals with excessive DA should benefit the least from load-induced endogenous DA, reflected in weak blood-oxygenlevel-dependent (BOLD) modulation across load. By contrast, individuals with insufficient DA should benefit more from task-induced DA, given that they have sufficient receptors. Individuals with balanced DA systems, irrespective of level, are expected to be most similar in terms of their BOLD modulation. 


\section{Materials and Methods}

We have reported the Cognition, Brain, and Aging (COBRA) study design, recruitment procedure, imaging protocols, and details of the cognitive and lifestyle battery elsewhere (Nevalainen et al. 2015). The COBRA study is a prospective multimodal imaging study of DA, brain structure and function, and cognition, in normal aging. Here, we restrict the presentation to methodological details directly relevant to the present work. The study was approved by the local Ethical and Radiation Safety Committee of Umeå, Sweden, and all participants provided written informed consent prior to testing. Written consent was also acquired for storage of blood samples at the Department of Biobank Research at Norrland's University Hospital.

\section{Participants}

The initial sample included 181 healthy older individuals (6468 years of age; mean $=66.2 ; \mathrm{SD}=1.2 ; 81$ women), who were randomly selected from the population register of Umeå, a city in northern Sweden. Individuals with pathological deviations in brain and cognitive functions or circumstances that could bias task performance or obstruct imaging sessions (e.g., metal implants) were excluded. The resulting sample had lower prevalence of hypertension than nationwide reports $33 \%$ in COBRA, $\sim 50 \%$ nationwide) (Carlsson et al. 2008), normal or slightly increased body-mass index (>30 in $14.4 \%$ of the sample), and $17.7 \%$ consumed nicotine. PET data were excluded for 4 individuals with imperfect segmentation of MR images and PETMR image coregistration and for 1 individual with pathological deviations in the brain observed on the MR images. Genetic data were missing for 2 persons.

Thus, the effective sample included 175 individuals for the main analyses. Furthermore, 12 participants were excluded from the fMRI analyses, as their performance indicated failure to comprehend the task instructions (Salami et al. 2018).

\section{Image Acquisition}

Magnetic resonance (MR) imaging was performed with a 3 Tesla Discovery MR 750 scanner (General Electric), equipped with a 32channel phased-array head coil. PET was done with a Discovery PET/CT 690 scanner (General Electric).

\section{PET Imaging}

All participants underwent a PET scan (Discovery PET/CT 690; GE Healthcare) performed during resting-state conditions following an intravenous bolus injection of $250 \mathrm{MBq}\left[{ }^{11} \mathrm{C}\right]$ raclopride. Preceding the injection, a 5-min low-dose helical CT scan (20 mA, $120 \mathrm{kV}, 0.8 \mathrm{~s}$ per revolution) was obtained for PETattenuation correction. Following the bolus injection, a 55min 18 -dynamic scan was acquired $(9 \times 120,3 \times 180,3 \times 260$, $3 \times 300 \mathrm{~s})$. Attenuation- and decay-corrected PET images (47 slices, $25 \mathrm{~cm}$ field of view, $256 \times 256$-pixel transaxial images, voxel size $0.977 \times 0.977 \times 3.27 \mathrm{~mm}^{3}$ ) were reconstructed with the resolution-recovery iterative VUE Point HD-SharpIR algorithm GE Healthcare ( 6 iterations, 24 subsets, $3.0 \mathrm{~mm}$ postfiltering) supplied with the scanner, with a half maximum resolution of $3.2 \mathrm{~mm}$.

\section{Structural MR Imaging}

A 3D fast-spoiled echo sequence was used for acquiring anatomical T1-weighted images, collected as 176 slices with a thickness of $1 \mathrm{~mm}$. Time repetition $(\mathrm{TR})=8.2 \mathrm{~ms}$, flip angle $=12^{\circ}$, and field of view $=25 \times 25 \mathrm{~cm}$.

\section{fMRI}

BOLD-contrast sensitive scans were acquired using a T2*weighted single-shot gradient echoplanar-imaging sequence. Parameters were 37 transaxial slices, $3.4 \mathrm{~mm}$ thickness, $0.5 \mathrm{~mm}$ spacing, time echo (TE)/TR $=30 / 2000 \mathrm{~ms}, 80^{\circ}$ flip angle, $25 \times 25 \mathrm{~cm}$ field of view, and a $96 \times 96$ acquisition matrix. At the start, 10 dummy scans were collected. The functional data were acquired during a numerical $n$-back working-memory task described below.

\section{Image Processing}

PET Images

D2DR status was determined by calculating the non-displaceable $\left[{ }^{11} \mathrm{C}\right]$ raclopride binding potential, $\mathrm{BP}_{\mathrm{ND}}$ (Logan et al. 1996). In brief, the PET emission scan format was converted from DICOM to NIfTI, corrected for head movements, and then coregistered to the corresponding MR image using the Statistical Parametric Mapping software (SPM8, https://www.fil.ion.ucl.ac.uk/spm/). Regions of interest were delineated with the FreeSurfer 5.3 segmentation software (Fischl et al. 2002; Fischl et al. 2004; Han and Fischl 2007). The cerebellar gray matter was used as a reference region, due to negligible D2DR expression (Farde et al. 1986). Time-activity curves for the reported regions were used to calculate $\mathrm{BP}^{\mathrm{ND}}$, which equals to distribution volume ratio-1, using the Logan method (Logan et al. 1996), with linear regression from 18 to 55 minutes. Median $\mathrm{BP}_{\mathrm{ND}}$ data were extracted from Brodmann areas 9 and 46 based on masks from the MRIcron atlas (http://people.cas.sc.edu/rorden/mricron/ index.html) to indicate D2DRs in dlPFC. In addition, $\mathrm{BP}_{\mathrm{ND}}$ data were extracted for the caudate based on the subcortical parcellations in Freesurfer.

To adjust for mean differences between Brodmann area 9 (Mean $=0.10 ; \mathrm{SD}=0.04)$ and $46(\mathrm{Mean}=18 ; \mathrm{SD}=0.04$; paired $\mathrm{t}$ test: $t(174)=39.3, P=0.000)$, values were $z$-transformed before averaging, and the sum score was converted to a t-score. For consistency, the caudate $\mathrm{BP}_{\mathrm{ND}}(\mathrm{Mean}=2.26 ; \mathrm{SD}=0.24)$ is also presented in t-score metric.

Using a low-affinity ligand, such as $\left[{ }^{11} \mathrm{C}\right]$ raclopride, to assess extrastriatal D2 binding potential deserves some comments, because of the low density of D2 receptors outside striatum. Toward this end, COBRA work has demonstrated that $\left[{ }^{11} \mathrm{C}\right]$ raclopride-based extrastriatal D2 binding may be meaningfully linked to working and episodic memory (Lövdén et al. 2017; Salami et al. 2018) and exhibits excellent psychometric properties (Papenberg et al., in preparation). Other research has also shown good test-retest reliability for extrastriatal binding of $\left[{ }^{11} \mathrm{C}\right]$ raclopride to D2DRs (Alakurtti et al. 2015). These patterns of data substantiate the feasibility of $\left[{ }^{11} \mathrm{C}\right]$ raclopride in measuring D2DR binding outside the striatum, despite the sparse number of receptors.

\section{fMRI Analyses}

SPM8 was used for preprocessing and data analysis of the fMRI task. Preprocessing of the task fMRI data included slicetiming correction, unwarping and realignment of the timeseries to the first image of each volume, and normalization to a sample-specific template (using DARTEL), followed by affine alignment to Montreal Neurological Institute (MNI) standard space. Data were resampled to $2-\mathrm{mm}$ isotropic voxels and 
spatially smoothed using an 6-mm full width at half maximum (FWHM) Gaussian kernel. First-order task analyses included the experimental conditions (1-back, 2-back, and 3-back) as regressors of interest in a general linear model, convolved with a hemodynamic response function. The six realignment parameters were included as covariates of no interest to account for residual movement artifacts. To obtain measures of brain activity across load in the 3 working memory conditions, fMRI contrast estimates (betas) were extracted from the relevant contrast images for the dlPFC (Salami et al. 2018), defined a priori as a key region of the frontal-parietal control network (see Vincent et al. 2008 for center MNI coordinates).

\section{Volumetric MRI Processing}

Gray-matter volumes were used as covariates in the analyses reported below. To quantify volumes, T1-weighted images were first segmented into gray matter, white matter, and cerebrospinal fluid, using the unified segmentation approach (Ashburner and Friston 2005) in SPM (Wellcome Trust Centre for Neuroimaging, http://www.fil.ion.ucl.ac.uk/spm/), implemented in Matlab 10 (The Mathworks, Inc). The "light clean up" option was used to remove odd voxels from the segments. The graymatter images were further analyzed using DARTEL in SPM. The gray-matter segments were imported into DARTEL space, and a final customized template was created, as were subject-specific flow fields containing the individual spatial-normalization parameters (diffeomorphic nonlinear image registration). These segments were further warped into standard MNI space, by in corporating an affine transformation mapped from the DARTEL template to MNI space. In addition, the normalized gray-matter volumes were modulated by scaling these with Jacobian determinants from the registration step to preserve local-tissue volumes. Volumes were smoothed with an FWHM Gaussian kernel of $8 \mathrm{~mm}$ in 3 directions. Masks from the MRIcron atlas were used to extract gray-matter volumes from Brodmann areas 9 and 46 . The caudate masks were based on the WFU Pickatlas AAL.

\section{Cognitive Measures}

The main cognitive domains examined offline in COBRA are working memory, episodic memory, and perceptual speed (see Nevalainen et al. 2015 for a more detailed description). These domains were tested with 3 separate tasks each (a verbal, a numerical, and a figural task). For each task, summary scores were computed across the total number of blocks or trials. A summary score per ability was created by averaging the T-scored measures $(M=50 ; S D=10)$ for each cognitive domain. Here, we restrict our description to the measures of working and episodic memory.

\section{Working Memory}

\section{Letter-updating Task}

A sequence of letters (A-D) appeared one-by-one on the computer screen, and participants were instructed to continuously update and remember the three lastly shown letters. Letters were presented during $1 \mathrm{~s}$, with an inter-stimulus interval (ISI) of $0.5 \mathrm{~s}$. Then, at an unknown time point in the sequence, the 3 last letters were to be typed using the keyboard. In case of failure, participants guessed. The test consisted of 16 trials, with 4 trials of $7,9,11$, or 13 letter sequences presented in random order $(\max =16$ trials $\times 3$ responses $=48)$.
Columnized Numerical 3-back Task

A grid consisting of $1 \times 3$ boxes was presented on the screen. In each box, one at a time and starting from the left, a number (19) was presented for $1.5 \mathrm{~s}$, with the next number presented after an ISI of $0.5 \mathrm{~s}$. After a number was presented in the rightmost box, the next number appeared in the leftmost box. In each trial, 30 numbers were presented. The task consisted of deciding whether the number appearing in a specific box was the same as the last number displayed in that particular box. A response was required for all three boxes throughout the test, by pressing labeled keys on the keyboard that corresponded to 'yes' (right index finger) or 'no' (left index finger). The first 3 numbers all received a 'no', as no numbers had appeared before that ( $\max 4$ trials $\times 27$ numbers $=108$ ).

\section{Spatial-updating Task}

Participants were presented with 3 separate grids $(3 \times 3$ squares in each) placed adjacent to each other. Three circular objects, one at a random position in each grid, were presented simultaneously for $4 \mathrm{~s}$, after which they disappeared. Following this, an arrow appeared beneath each grid for $2.5 \mathrm{~s}$ (one at a time, from left to right, with an ISI of $0.5 \mathrm{~s}$ ), pointing in the direction where each circle should be mentally moved. This manipulation was done twice for each grid (i.e., 6 updating operations in total). Following updating, participants were asked to mark the correct object position in each grid, using the computer mouse. In case of uncertainty, participants guessed the position of the object. The test consisted of 10 test trials $(\max =30)$.

\section{In-scanner Numerical n-back Task}

The sum of correct responses was obtained from a numerical $n$ back task. In this task, a sequence of single numbers appeared on the screen. Each number was shown for $1.5 \mathrm{~s}$, with an ISI of $0.5 \mathrm{~s}$. During every item presentation, participants reported if the number currently seen on the screen was the same as that shown 1, 2, or 3 digits back. A heading that preceded each subtest indicated the actual condition. Participants responded by pressing one of two adjacent buttons with the index or middle finger to reply 'yes, it is the same number' or 'no, it is not the same number', respectively. A total of 9 blocks for each condition (1-back, 2-back, and 3-back) were performed in random order, each block consisting of 10 items. The trial sequence was the same for all participants. In calculating the total score, each correct answer was given 1 credit point, except for the first item in each 1-back condition, and for items 1 to 2 and 1 to 3 in each 2- and 3-back condition. Thus, the maximum score for each condition was 81,72 , and 63 .

\section{Episodic Memory}

Word-recall Task

Participants were presented with 16 Swedish nouns that appeared consecutively on the screen. The words were concrete, easy to spell, and all differed in the first three letters. During study, words were presented for $6 \mathrm{~s}$ each, with an ISI of $1 \mathrm{~s}$. After having seen the entire list of 16 items, participants reported the words they could recall by writing them down one-by-one in any order using a keyboard. Two test trials were administered $(\max =32)$

Number-word Task

This task consisted of memorizing pairs of 2-digit numbers and concrete plural nouns (e.g., 46 dogs). During study, 8 number- 
word pairs were displayed for $6 \mathrm{~s}$ each, with an ISI of $1 \mathrm{~s}$. Following study, participants were requested to report, using the keyboard, the 2-digit number associated with each noun shown on the screen (e.g., How many dogs?). Upon reporting, words were presented one-by-one in a different order than during acquisition. A total of 2 test trials were administered $(\max =16)$.

\section{Object-position Task}

Participants were presented with a grid of $6 \times 6$ squares. A total of 12 objects were shown, one at a time, each at separate locations in the grid. Presentation time of each object-position pair was $8 \mathrm{~s}$, with an ISI of $1 \mathrm{~s}$. At test, all objects were shown adjacent to the grid, and the correct position of each object was reported by moving objects with the computer mouse (in any order) to the correct location in the grid. If failing to recall the position, participants guessed. A total of 2 test trials were performed $(\max =24)$.

\section{Genotyping}

The COMT Val158Met polymorphism (rs4680) was chosen as a genetic proxy for differences in endogenous DA (Lotta et al. 1995). In conjunction with the PET session, blood samples were collected from all participants and stored at the local biobank. DNA extraction and genotyping services were performed by LGC genomics, using their in-house products. In brief, DNA was extracted from the buffy-coat fraction of blood samples using the Kleargene ${ }^{\mathrm{TM}}$ XL nucleic acid extraction kits, and genotyping was performed with KASPTM genotyping assays. When conducting the genotyping analysis, the DNA template was mixed with a KASP master mix [containing KASP Taq polymerase, deoxynucleoside triphosphates, buffers, salts, two fluorescently-labeled (FAM and HEX) reporter cassettes], and a single-nucleotide polymorphism-specific KASP Assay mix (containing two allele-specific forward primers and one common reverse primer). The sequence for the forward primers was 5'-GCA TGC ACA CCT TGT CCT TCA C/T-3' (i.e., differing at one base in the $3^{\prime}$-end) and for the reverse primer: $5^{\prime}$-CAT CAC CCA GCG GAT GGT GGA T-3'. Genotyping was carried out with polymerase chain reaction sessions, during which primers bound to their target sequences, reporter cassettes were incorporated in the DNA product, and amplification of the product was achieved. Allelic variants were determined via detection of FAM or HEX fluorescence for homozygotes or both for heterozygotes. DNA amplification failed for one sample.

The distribution of COMT alleles was in Hardy-Weinberg equilibrium (Met/Met: $n=54$; Met/Val: $n=85$; Val/Val: $n=38$; $\left.\chi^{2}<1, p>0.1\right)$. In the effective sample, there were $52 \mathrm{Met}$ homozygotes due to missing PET data. Notably, COMT genotypes did not differ with respect to $\mathrm{BP}_{\mathrm{ND}}$ in dlPFC, $F(1$, $174)=1.49, P=0.228$, or caudate, $F(1,173)=1.91, P=0.151$. The comparison between Met and Val homozygotes was at trend level for the dlPFC (see Supplementary Table A1; $P=0.10$; partial eta-squared $=0.030$ ), but not after adjusting for sex $(P=0.17$; partial eta-squared $=0.022)$. To address potential concerns, we conducted further control analyses. Specifically, we created dummy variables to code for the effects of COMT, which were partialled out from dlPFC $\mathrm{BP}_{\mathrm{ND}}$ before conducting the main regression analyses reported below. These additional analyses did not result in any change of results.

\section{Statistical Analyses}

Behavioral and demographic data were analyzed using SPSS for Windows 15 (SPSS). We conducted linear regression analyses to investigate main and interactive effects between $\mathrm{BP}_{\mathrm{ND}}$ (dlPFC and caudate) and COMT status (Met/Met, Met/Val, and Val/Val) on cognition. Separate regression analyses were conducted for the 2 memory domains. Given that COMT may influence cognition both in a dose-response manner as well as nonlinearly (Nyberg et al. 2014; Papenberg et al. 2014), with one genotype showing differential performance, we also tested for potential nonlinear effects of COMT as well as the interaction term with $\mathrm{BP}_{\mathrm{ND}}$.

For illustrative purposes and further analyses, participants were grouped into low and high D2DR availability groups based on a median split of the sample distribution of $\mathrm{BP}_{\mathrm{ND}}$ in the region of interest (i.e., mean of left and right Brodmann areas 9 and 46 for dlPFC and caudate). This resulted in the following distribution of COMT across groups: low dlPFC-D2DR BP $\mathrm{ND}_{\mathrm{ND}}$ $(\mathrm{Met} / \mathrm{Met}=30 ; \mathrm{Met} / \mathrm{Val}=44 ; \mathrm{Val} / \mathrm{Val}=13)$ and high $\mathrm{dlPFC}-\mathrm{D} 2 \mathrm{DR}$ $\mathrm{BP}_{\mathrm{ND}}(\mathrm{Met} / \mathrm{Met}=22 ; \mathrm{Met} / \mathrm{Val}=41 ; \mathrm{Val} / \mathrm{Val}=25)$. The corresponding distributions for the groups based on caudate $\mathrm{BP}_{\mathrm{ND}}$ were: low D2DR BP $\mathrm{ND}(\mathrm{Met} / \mathrm{Met}=24 ; \mathrm{Met} / \mathrm{Val}=39 ; \mathrm{Val} / \mathrm{Val}=24)$ and high D2DR BP ${ }_{\text {ND }}(\mathrm{Met} / \mathrm{Met}=27 ; \mathrm{Met} / \mathrm{Val}=46 ; \mathrm{Val} / \mathrm{Val}=14)$. Reported mean differences stem from a repeated-measures multivariate analysis of covariance (MANCOVA), with D2DR group (low and high) and COMT status (Met/Met, Met/Val, and Val/Val) as between-subject factors and cognitive performance (working memory and episodic memory) as the outcome.

Given the well-established female superiority in episodic memory (Herlitz et al. 1997) and the impact of education on memory (Nyberg et al. 2012), sex and education were included as covariates in all analyses. For the analyses involving caudate $\mathrm{BP}_{\mathrm{ND}}$, we controlled for variation in the DA transporter (DAT) gene (Li et al. 2013), because DAT is involved in DA degradation in striatum (Bäckman et al. 2006). Moreover, all analyses were adjusted for the D2DR C957T polymorphism, as it may inflate $\left[{ }^{11} \mathrm{C}\right]$ raclopride $\mathrm{BP}_{\mathrm{ND}}$ in individuals with high affinity (Karalija et al. 2019)

With respect to BOLD activations, a paired t-test indicated no differences between 1-back and 3-back in the right hemisphere $t(164)=0.78, P=0.434$, in line with data showing that the left hemisphere is most sensitive to WM demands (Nyberg et al. 2014). Moreover, there were no differences between 2-back and 3-back in the left hemisphere, $t(164)=0.58, P=0.564$. Therefore, the analyses focused on the left hemisphere and the contrast between 1-back and 3-back to maximize the power to detect differences. We conducted a repeated-measures MANCOVA, with D2DR group (low and high) and COMT status (Met/Met, Met/Val, and Val/Val) as between-subject factors and BOLD activity (1back and 3-back) as the outcome. In addition to sex and education, gray-matter volume in dlPFC was included as covariate.

The Outlier Labeling Rule was used to track univariate outliers; the following formulas were computed to calculate the upper and lower limits, respectively, for outliers: Q3+[2.2* (Q3-Q1)] and Q1-[2.2*(Q3-Q1)], where Q1 is the lower quartile (25th percentile of the data) and Q3 is the upper quartile (75th percentile). The number 2.2 is the value of the tuning parameter $\mathrm{g}$, which was set to 2.2 following recommendations (Hoaglin and Iglewicz 1987). Multivariate outliers within and across groups were determined using Mahalanobi's distance, with the recommended $P<0.001$ threshold for the $\chi^{2}$ value (Tabachnick and Fidell 2006). For all analyses, the alpha level was set to $P<0.05$. Effect sizes are indicated by partial eta squared. 

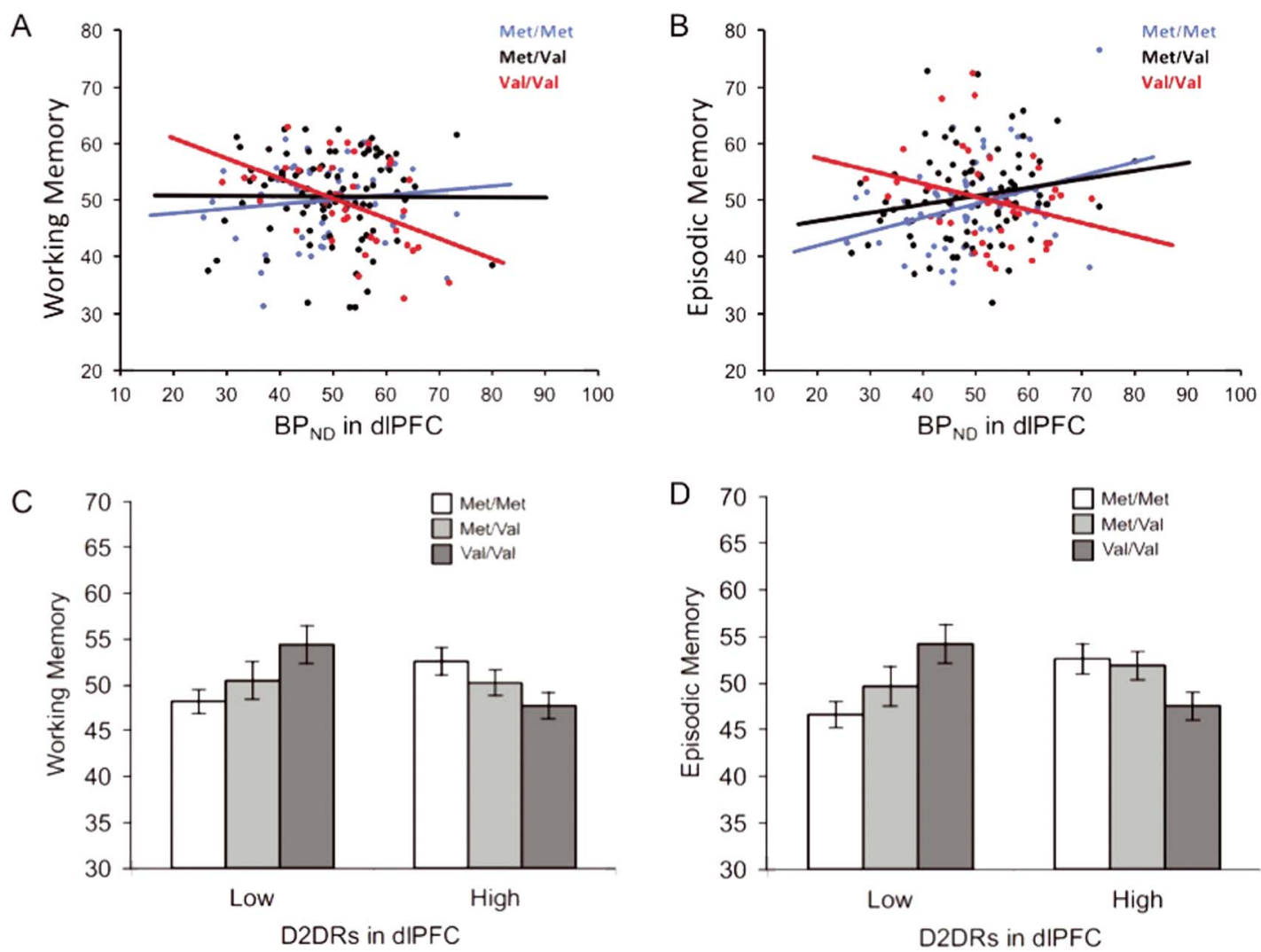

Figure 2. Working memory $(A, C)$ and episodic memory $(B, D)$ performance as a function of COMT genotype (Met/Met, Met/Val, and Val/Val) and D2DR BP $\mathrm{ND}$ (low and high) in dlPFC. $\mathrm{BP}_{\mathrm{ND}}$ is shown in t-score metric and ranges from 25.8 to 80.2 . Errors bars represent 1 standard error around the means.

\section{Results}

\section{Interactive Effects between D2DR BP $\mathrm{ND}$ and COMT Status on Cognitive Performance}

$\mathrm{BP}_{\mathrm{ND}}$ in dlPFC was not directly related to memory performance (working memory: $\beta=-.059, \mathrm{t}(167)=-.804, \mathrm{P}=0.423$; episodic memory: $\beta=0.086, \mathrm{t}(168)=1.179, P=0.240)$ and neither was COMT (working memory: $\beta=0.026, \mathrm{t}(167)=0.357, \mathrm{P}=0.722$; episodic memory: $\beta=0.049, \mathrm{t}(168)=0.680, \quad \mathrm{P}=0.497)$. The regression analyses revealed a significant linear interaction between $\mathrm{BP}_{\mathrm{ND}}$ in dIPFC and COMT in predicting working $(\beta=-0.524$, $t(166)=-2.594, \quad P=0.010 ; \quad$ Fig. $2 A)$ and episodic $(\beta=-0.488$, $t(167)=-2.426, \quad P=0.016 ; \quad$ Fig. $2 B)$ memory. There were no interactive effects between $\mathrm{BP}_{\mathrm{ND}}$ in caudate and COMT on memory performance. However, the nonlinear interaction between caudate $\mathrm{BP}_{\mathrm{ND}}$ and COMT was significant for episodic memory $(\beta=-2.096, t(163)=-2.577, P=0.011$; Fig. 3B) but not for working memory $(P>0.158$; Fig. $3 A)$.

Notably, adjusting the analyses for gray-matter volume in dlPFC or caudate, the pattern of results remained, suggesting that partial-volume effects were negligible (correlation between $\mathrm{BP}_{\mathrm{ND}}$ and volume: $r_{\mathrm{dlPFC}}=0.055, \mathrm{P}=0.467$ and $r_{\text {caudate }}=0.047$, $P=0.534)$. The interaction between COMT and $\mathrm{BP}_{\mathrm{ND}}$ in dlPFC were as follows: working memory $(\beta=-0.442, \mathrm{t}(164)=-2.188$, $P=0.030)$ and episodic memory $(\beta=-0.417, t(165)=-2.062$, $P=0.041)$. The nonlinear interaction between COMT and BP in caudate remained significant as well $(\beta=-2.045, \mathrm{t}(161)=-2.500$, $P=0.013$ ). To rule out that COMT may have influenced $B P_{N D}$ dlPFC and consequently the pattern of results, we repeated the above analyses with $\mathrm{BP}_{\mathrm{ND}}$ in dIPFC, after adjusting for COMT (coded as two dummy variables). The interaction between COMT and $\mathrm{BP}_{\mathrm{ND}}$ in dlPFC remained almost identical for both memory functions: working memory $(\beta=-0.520, t(166)=-2.588, P=0.011)$ and episodic memory $(\beta=-0.461, t(167)=-2.299, P=0.023)$.

Figure 2 also depicts performance in working memory (Fig. 2C) and episodic memory (Fig. 2D) as a function of dlPFC$\mathrm{D} 2 \mathrm{DR} \mathrm{BP}_{\mathrm{ND}}$ group (lower and higher) and COMT genotype. Follow-up comparisons indicated that Met homozygotes with low D2DR $\mathrm{BP}_{\mathrm{ND}}$ in dlPFC performed worse than Met homozygotes with high $\mathrm{D} 2 \mathrm{DR} \mathrm{BP}_{\mathrm{ND}}$ with respect to both working $(t(51)=1.98, P=0.050$, partial eta squared $=0.023)$ and episodic $(t(51)=2.55, P=0.012$, partial eta squared $=0.038)$ memory. By contrast, Val homozygotes in the low D2DR group had better working, $t(36)=2.46, P=0.015$, partial eta squared $=0.036$, and episodic memory, $t(36)=2.58, P=0.011$, partial eta squared $=0.039$, than those in the high D2DR group. Heterozygotes did not differ from each other in the low and high D2DR groups (episodic memory: $P=0.100$; working memory: $P=0.970$ ).

With respect to the D2DR groups based on caudate $\mathrm{BP}_{\mathrm{ND}}$ (Fig. 3C and D), Val homozygotes in the high caudate-D2DR group performed worse than Val homozygotes in the low caudate-D2DR group for episodic memory $(t(36)=2.16, P=0.032$, partial eta squared $=0.028$ ). Similarly, heterozygotes in the high caudate-D2DR group showed better performance than heterozygotes with low D2 $\mathrm{BP}_{\mathrm{ND}} \mathrm{t}(82)=3.99, P=0.000$, partial eta squared $=0.090)$. There were no differences between Met homozygotes in the two groups $(P=0.283)$. 
A
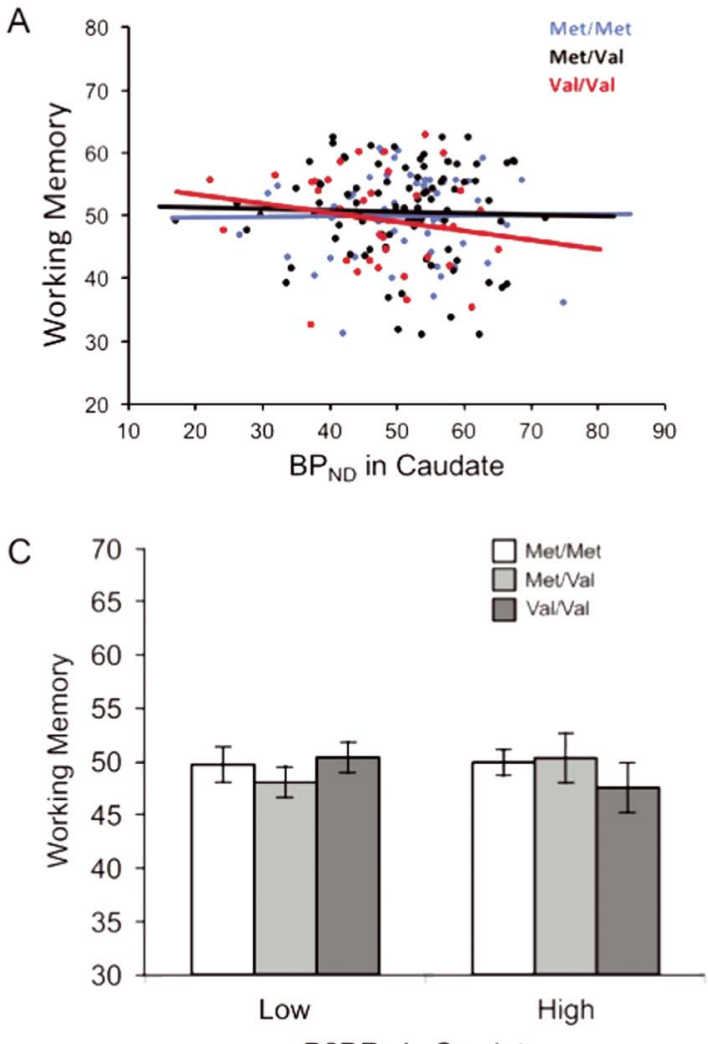

D2DRs in Caudate
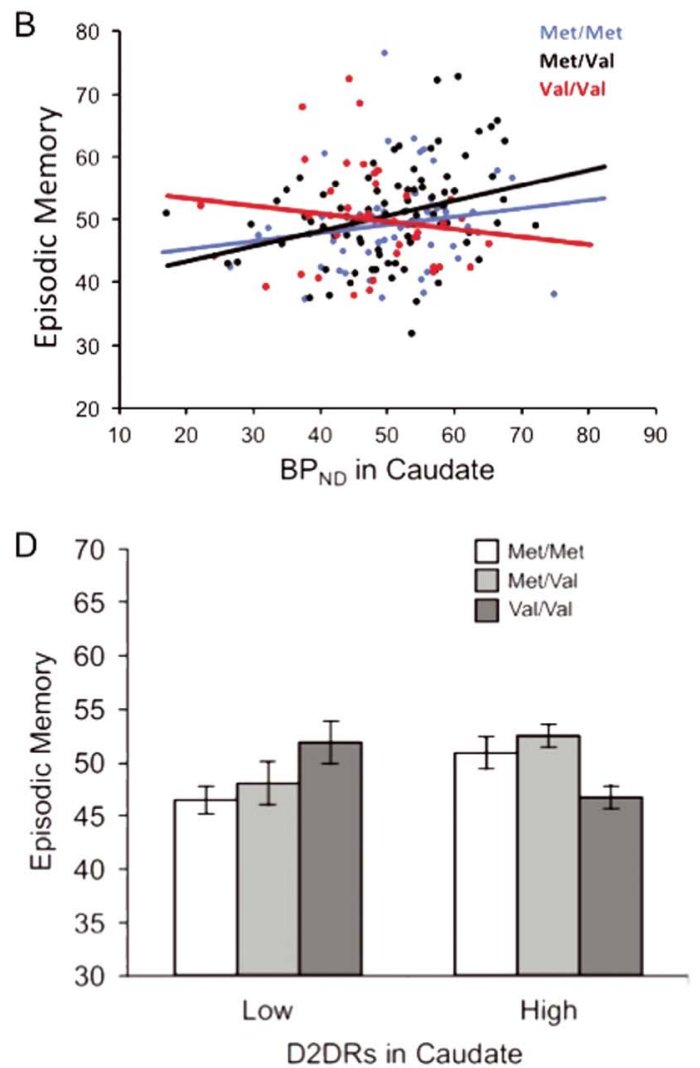

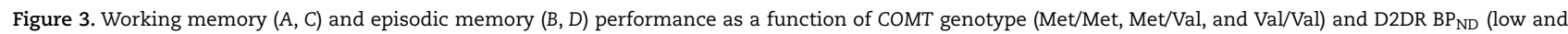
high) in caudate. $\mathrm{BP}_{\mathrm{ND}}$ is shown in t-score metric and ranges from 17.2 to 74.9. Errors bars represent 1 standard error around the means.

\section{BOLD Modulation Differences in dlPFC between Groups with Varying Balance between Availability of DA and D2DR}

BOLD modulation (3-back vs. 1-back) was related to offline working-memory performance $(r=0.284, P=0.000$; cf. Salami et al. 2018). The analyses involving all 6 groups did not yield any significant effects. To increase power, we focused on the groups with the largest discrepancies between transmitter availability and receptor binding. Figure $4 \mathrm{~A}$ depicts BOLD activations and $3 B$ BOLD modulation ( 3 vs. 1 ) for the 4 groups in question. The analyses showed a significant triple interaction among dlPFC-D2DR group, COMT status, and condition (1-back and 3back), $F(1,75)=4.07, P=0.047$, partial eta-squared $=0.051$. Followup comparisons revealed no differences between conditions for Met homozygotes in the low D2DR group, indicating no significant BOLD modulation, $t(25)=0.77, P=0.442$. By contrast, Val homozygotes with low D2DRs in dlPFC show significant BOLD modulation, $t(11)=2.33, P=0.023$, which was similar in Met, $t(18)=2.83, P=0.006$, and Val homozygotes with high D2DRs, $\mathrm{t}(24)=2.43, \mathrm{P}=0.018$.

Moreover, there were no behavioral differences in the scanner task based on a sum score across conditions (dlPFC-D2DR group $\times$ COMT: $P>0.2$ ), and there were no differences between 2-back and 3-back in any of the groups (Ps $>0.2$ ).

\section{Discussion}

The main goal of this study was to examine whether the balance between DA transmitter availability and receptor status in PFC influences cognitive performance. We show that genetic predispositions for endogenous DA (COMT) interact with D2DR availability, such that the balance between DA availability and receptor status is associated with relatively better working and episodic memory and thus contributes to inter-individual differences in cognition. Our findings are in line with the role of prefrontal dopaminergic modulation in both working (Kimberg et al. 1997; Liggins 2009; Williams and Goldman-Rakic 1995; Rieckmann et al. 2011) and episodic memory (Wimber et al. 2011; de Frias et al. 2004). Specifically, the prefrontal DA system has a role in maintenance and updating of working memory representations (D'Esposito and Postle 2015). With respect to episodic memory, higher prefrontal DA availability has been linked to better suppression of irrelevant long-term memories (Wimber et al. 2011).

Previously, we have reported that D2DRs in caudate are associated with episodic memory (Nyberg et al. 2016), in line with their role in supporting hippocampus-based functioning (Brown et al. 2012; Müller et al. 2018). Moreover, high striatal and extrastriatal D2DR availability was associated with high cognitive performance, but there was a smaller group of individuals for which high D2DR availability, particularly in striatum, was associated with poor performance, especially for working memory (Lövdén et al. 2018). In the present analysis, only the association between caudate and episodic memory, but not working memory, was modulated by COMT, showing a similar pattern as in the dlPFC, indicating a nonlinear relationship between COMT status and D2 availability. Although it is generally thought that the COMT alleles have codominant effects, previous studies have not always 
A

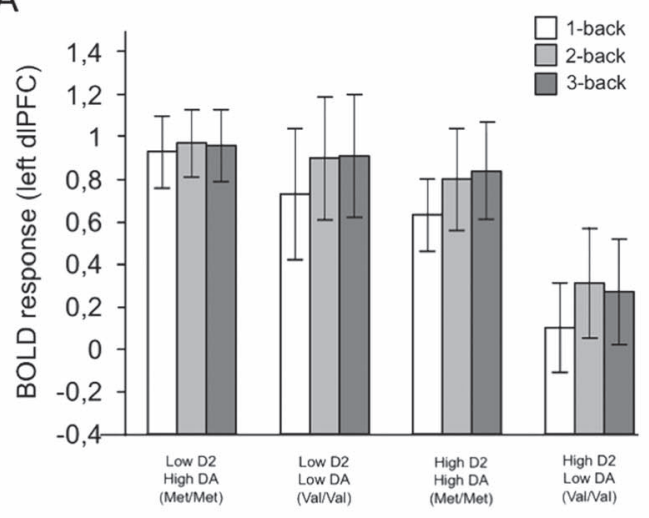

B

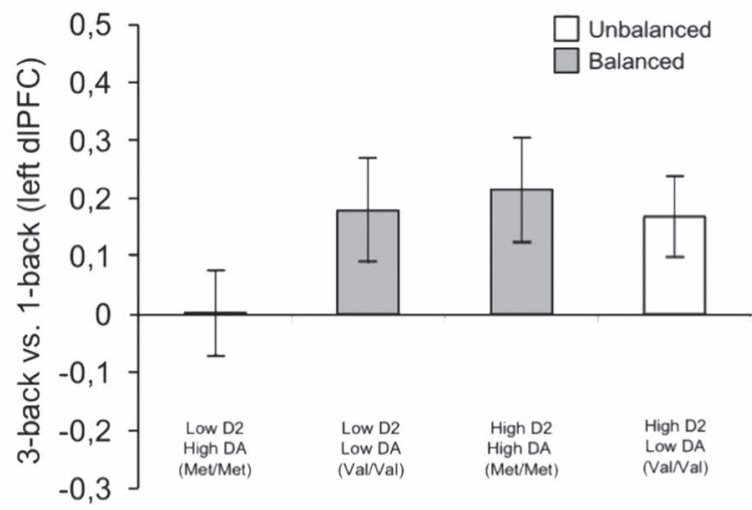

Figure 4. (A) BOLD responses during the $3 n$-back conditions and (B) BOLD modulation (3-back minus 1-back) in left dlPFC for the groups with the largest balance and imbalance between DA availability and receptor status in dlPFC. Errors bars represent 1 standard error around the means.

found dose-reponse relationships (Witte and Floel 2012), which we observed in dlPFC only. Thus, the nonlinear genetic effects in combination with caudate D2DR availability may be due to the fact that COMT is less involved in striatal DA metabolism (Yavich et al. 2007), resulting in weaker genotype differences. The COMT enzyme is crucial for regulating frontal DA transmission and accounts for over $60 \%$ of total DA turnover, as compared with only $15 \%$ in striatum (Karoum et al. 1994). The low COMT expression and our previous findings of a particularly strong negative relationship between working memory and D2DRs in a subgroup of participants may underlie the non-significant interactive effects between COMT and D2DR availability in caudate for working memory. Importantly, the observation of a similar pattern of results in the striatum support the validity of extrastriatal D2DR availability assessment with $\left[{ }^{11} \mathrm{C}\right]$ raclopride, which has been controversial due to the low D2DR availability in the neocortex.

Our findings are in line with the inverted-U-shaped function depicting the relationship between DA activity and cognitive performance, with too low and too high dopaminergic tone being associated with lower cognitive functioning. This pattern has mostly been observed in PFC but has also been reported in striatum (Cools and D'Esposito 2011; Gjedde et al. 2010; Takahashi et al. 2008) Accordingly, optimal DA signaling results in maximal function and insufficient or excessive levels lead to dysfunction (Lövdén et al. 2018; Jacobs and D'Esposito 2011). That said, our data suggest a modification of the inverted-U account, stressing the dynamic interplay between endogenous DA availability and receptor status. Based on the inverted-U function, one could have predicted that individuals who are low or high with respect to both endogenous DA availability and D2DR status would be most removed from the apex of the curve and perform worst. On the contrary, we found that Val homozygotes (i.e., low endogenous DA) and high D2DR availability and Met homozygotes (with high endogenous DA) in combination with low D2DR availability performed poorly, presumably due to insufficient and excessive DA transmitter availability, respectively, relative to the number of receptors.

Functional imaging data provide further support for this line of reasoning. During an $n$-back task, Met homozygotes with low D2DR availability were not able to upregulate their BOLD activity in dlPFC during a more demanding condition (3-back vs. 1-back). This is consistent with our previous results that a subgroup that showed no load-dependent BOLD modulation had lower performance and frontal D2DRs availability (Salami et al. 2018). By contrast, Val homozygotes with low D2DR showed significant BOLD modulation in the present data, underscoring that the balance between endogenous DA and receptors is crucial for optimal cognitive functioning. The latter group did not differ from the balanced Met homozygotes (i.e., high D2DR status) or from Val homozygotes with high D2DR levels, who also benefited from tasked-induced DA, presumably due to high D2DR availability. The lack of differences in BOLD modulation among the latter 3 groups may also be due to the small sample size in the different groups. Older age, COMT Val, as well as other genetic risk profiles have been associated with larger upregulation of BOLD activity during easier tasks as compared with more difficult tasks (Krug et al. 2018; Nyberg et al. 2014). For instance, younger adults and Met carriers showed maximal dlPFC BOLD response during manipulation of working-memory content, whereas older adults and Val carriers displayed elevated dlPFC responses during a less demanding maintenance condition, suggesting an inefficient BOLD signal (Nyberg et al. 2014). Thus, it is conceivable that Val homozygotes with high DRDRs may also show a stronger BOLD response during 2-back than 3-back with larger sample sizes in each group (Nyberg et al. 2014). That said, a recent metaanalysis did not find a systematic influence of COMT on brain activation during working-memory tasks (Nickl-Jockschat et al. 2015). This is also related to behavioral data on the relationship between COMT and cognitive performance. Although the majority of studies have linked the Met allele to better performance in working and episodic memory (Witte and Floel 2012), there is research that has failed to find a genotype effect (Laukka et al. 2013; Wardle et al. 2013) or even reported the opposite pattern (Wang et al. 2013). Apart from the genotype effect, PET studies investigating DA-cognition links have not always been able to reveal significant associations (see Juarez et al., 2018 for discussion). These mixed findings may partly reflect the fact that the balance between DA receptors and transmitter availability was not taken into account.

Overall, the observed pattern of results is in line with DA's role in the modulation of the signal-to-noise ratio of information processing in the brain (Winterer and Weinberger 2004; Li et al. 2001). Specifically, our data suggest that in individuals with high D2DR binding, increasing levels of endogenous DA are beneficial and result in better performance. Evidence for beneficial effects 
of DA have been documented in different lines of research. In vivo, DA release amplifies signal information and reduces spontaneous firing, leading to an increase in signal-to-noise ratio for neurons responding to stimuli (Vander Weele et al. 2018). In vitro, it has been shown that DA facilitates synaptic plasticity, such as long-term potentiation, and this effect follows an invertedU-shaped concentration curve (Kolomiets et al., 2009). While increasing levels of DA result in a stronger excitatory postsynaptic potential, excessive DA again decreases the signal. In healthy humans, experimental depletion of DA resulted in increased signal variability and decreased network connectivity (Shafiei et al., 2019), suggesting less stable and noisier neural signals. In line with the latter finding, computational models simulating agingrelated decline in dopaminergic modulation (Fig. 1, decline portion of the inverted-U-shaped function) result in more variable and less distinct neural activations (Li et al. 2001; Li \& Sikström, 2002). Finally, higher D2 receptor availability has been found in unmedicated patients with Parkinson's disease, suggesting a compensatory mechanism resulting from low DA levels (e.g., Kaasinen et al. 2000; Thobois et al., 2004). Thus, low DA status may have exacerbated the imbalance between transmitter and receptor availability in our sample of healthy older adults.

As noted, previous work demonstrates that administration of a D2 agonist in nonhuman primates impaired working memory and induced "hallucinatory-like" behaviors (Arnsten et al. 1995). This is in line with the hypothesis that excessive D2DR activation contributes to prefrontal dysfunction in schizophrenia (Winterer and Weinberger 2004; Durstewitz and Seamans 2008). Moreover, stimulation of D2DRs can elicit a $\mathrm{Ca}(2+)$-channeldependent afterdepolarization in prefrontal neurons through which they might increase the level of noise in prefrontal circuits (Gee et al. 2012).

The fact that we are emphasizing the importance of balance between endogenous DA and receptor status for cognitive functioning does not imply that levels are unimportant, as demonstrated in age-comparative research and patient studies (Bäckman et al. 2006). Conceivably, in addition to having a balanced DA system, a certain level of transmitter availability and receptors has to be achieved to optimize performance. The importance of level is acknowledged in Figure 1. The dynamic interplay between DA levels and receptor status should be investigated in future studies, preferably with longitudinal designs to determine the effects of aging on individual differences in this balance. Although we did not find any differences in performance or BOLD modulation among the balanced groups, balanced Val homozygotes may show performance impairments before Met homozygotes as a function of aging-related decline in the DA system.

An important limitation should be acknowledged. BP measurements with $\left[{ }^{11} \mathrm{C}\right]$ raclopride in healthy human populations are considered to reflect D2DR density (Farde et al. 1995). However, $\mathrm{BP}_{\mathrm{ND}}$ is not a pure assessment of the number of receptors, as it may also reflect affinity (i.e., BP = receptor density $*$ affinity). Indeed, studies have demonstrated interindividual differences in $\left[{ }^{11} \mathrm{C}\right]$ raclopride affinity (Hirvonen et al. 2009), which are likely related to differences in extracellular DA levels. Thus, it is conceivable that differences in DA tone among COMT groups may contribute to the measures of $\mathrm{BP}_{\mathrm{ND}}$, with lower $\mathrm{DA}$ tone resulting in higher $\mathrm{BP}_{\mathrm{ND}}$. However, COMT did not affect $\mathrm{BP}_{\mathrm{ND}}$ in dlPFC or caudate in our study. This is in line with PET work on D2 $\mathrm{BP}_{\mathrm{ND}}$, which did not find any differences in $\mathrm{BP}$, density, or affinity among COMT groups (Hirvonen et al. 2010). A study using PET assessment of D1 receptors (Slifstein et al. 2008), which is not sensitive to endogenous DA (Cervenka 2019), showed that Val carriers had elevated BP. Thus, it is more likely that differences in $\mathrm{BP}_{\mathrm{ND}}$ reflect upregulation of receptors due to low DA tone. Taken together, it is very unlikely that our measures of $\mathrm{BP}_{\mathrm{ND}}$ reflect endogenous DA differences among COMT genotypes influencing the observed pattern of results.

In summary, our study provides novel information on the importance of balance between prefrontal DA transmitter availability and receptor status for human memory in aging. Consequently, our findings have implications for the assessment of dopaminergic neuromodulation in healthy humans as well as in patient populations. Given that pre- and postsynaptic DA markers are not necessarily correlated in early adulthood (Berry et al. 2018; Karrer et al. 2017), it is likely that an imbalanced DA system is not specific to old age but may become more imbalanced with aging-related neurochemical decline or disease development (e.g., schizophrenia and alcoholism; Volkow et al. 1996; Kesby et al. 2018).

\section{Funding}

Swedish Research Council, Umeå University; Umeå UniversityKarolinska Institute Strategic Neuroscience Program; Knut and Alice Wallenberg Foundation; Torsten and Ragnar Söderberg Foundation; Alexander von Humboldt Research award; donation of the Jochnick Foundation; Swedish Brain Power; Swedish Brain Foundation; Västerbotten County Council; Innovation Fund of the Max Planck Society; 2010 Leibniz Research Award from the German Research Foundation (DFG).

\section{Notes}

The freesurfer analyses were performed on resources provided by the Swedish National Infrastructure for Computing (SNIC) at HPC2N in Umeå. Conflict of Interest: None declared.

\section{Author Contributions}

L.N., K.R., M.L., U.L., and L.B. designed the research; N.K. performed the research; G.P., N.K., M.A., A.R., A.S., and J.A. analyzed the data; G.P. and L.B. wrote the manuscript, which was edited by all authors.

\section{Data availability}

The data sets generated and analyzed during the current study are available from the corresponding author on reasonable request.

\section{References}

Alakurtti K, Johansson JJ, Joutsa J, Laine M, Bäckman L, Nyberg L, Rinne JO. 2015. Long-term test-retest reliability of striatal and extrastriatal dopamine D2/3 receptor binding: study with [11C] raclopride and high-resolution PET. J Cereb Blood Flow Metab. 35:1199-1205.

Arnsten AF, Cai JX, Steere JC, Goldman-Rakic PS. 1995. Dopamine D2 receptor mechanisms contribute to age-related cognitive decline: the effects of quinpirole on memory and motor performance in monkeys. J Neurosci. 15:3429-3439.

Ashburner J, Friston KJ. 2005. Unified segmentation. NeuroImage. 26:839-851. 
Bäckman L, Nyberg L, Lindenberger U, Li SC, Farde L. 2006. The correlative triad among aging, dopamine, and cognition: current status and future prospects. Neurosci Biobehav Rev. 30:791-807.

Bäckman L, Nyberg L, Soveri A, Johansson JJ, Andersson M, Dahlin E, Neely AS, Virta J, Laine M, Rinne JO. 2011. Effects of working-memory training on striatal dopamine release. Science. 333:718.

Berry AS, Shah VD, Furman DJ, White RL III, Baker SL, O'Neil JP, Janabi M, D'Esposito M, Jagust WJ. 2018. Dopamine synthesis capacity is associated with D2/3 receptor binding but not dopamine release. Neuropsychopharmacology. 43:1201-1211.

Brown TI, Ross RS, Tobyne SM, Stern CE. 2012. Cooperative interactions between hippocampal and striatal systems support flexible navigation. NeuroImage. 60:1316-1330.

Carlsson AC, Wandell PE, Faire U, Hellenius M-L. 2008. Prevalence of hypertension in immigrants and Swedish-born individuals, a cross-sectional study of 60-year-old men and women in Sweden. J Hypertens. 26:2295-2302.

Cervenka S. 2019. PET radioligands for the dopamine D1receptor: application in psychiatric disorders. Neurosci Letters. 691:26-34

Cools R, D'Esposito M. 2011. Inverted-U-shaped dopamine actions on human working memory and cognitive control. Biol Psychiatry. 69:e113-e125.

de Frias CM, Annerbrink K, Westberg L, Eriksson E, Adolfsson $R$, Nilsson LG. 2004. COMT gene polymorphism is associated with declarative memory in adulthood and old age. Behav Genet. 34:533-539.

D'Esposito M, Postle BR. 2015. The cognitive neuroscience of working memory. Annu Reu Psychol. 66:115-142.

Durstewitz D, Seamans JK. 2008. The dual-state theory of prefrontal cortex dopamine function with relevance to catecholO-methyltransferase genotypes and schizophrenia. Biol Psychiatry. 64:739-749.

Eriksson J, Vogel EK, Lansner A, Bergström F, Nyberg L. 2015. Neurocognitive architecture of working memory. Neuron. 88:33-46.

Farde L, Hall H, Ehrin E, Sedvall G. 1986. Quantitative analysis of D2 dopamine receptor binding in the living human brain by PET. Science. 231:258-261.

Farde L, Hall H, Pauli S, Halldin C. 1995. Variability in D2dopamine receptor density and affinity: a PET study with [11C] raclopride in man. Synapse. 20:200-208.

Fischl B, Salat DH, Busa E, Albert M, Dieterich M, Haselgrove C, van der Kouwe A, Killiany R, Kennedy D, Klaveness S et al. 2002. Whole brain segmentation: automated labeling of neuroanatomical structures in the human brain. Neuron. 33:341-355.

Fischl B, Salat DH, van der Kouwe A, Makris N, Segonne F, Quinn BT, Dale AM. 2004. Sequence-independent segmentation of magnetic resonance images. NeuroImage. 23:S69-S84.

Ford CP. 2014. The role of D2-autoreceptors in regulating dopamine neuron activity and transmission. Neuroscience. 282:13-22.

Gee S, Ellwood I, Patel T, Luongo F, Deisseroth K, Sohal VS. 2012. Synaptic activity unmasks dopamine D2 receptor modulation of a specific class of layer $\mathrm{V}$ pyramidal neurons in prefrontal cortex. J Neurosci. 32:4959-4971.

Gjedde A, Kumakura Y, Cumming P, Linnet J, Møller A. 2010. Inverted-U-shaped correlation between dopamine receptor availability in striatum and sensation seeking. Proc Natl Acad Sci U S A. 107:3870-3875.
Glickstein SB, Hof PR, Schmauss C. 2002. Mice lacking dopamine D2\&D3 receptors have spatial working memory deficits. J Neurosci. 22:5619-5629.

Han X, Fischl B. 2007. Atlas renormalization for improved brain MR image segmentation across scanner platforms. IEEE Trans Med Imaging. 26:479-486.

Herlitz A, Nilsson LG, Bäckman L. 1997. Gender differences in episodic memory. Mem Cogn. 25:801-811.

Hirvonen MM, Laakso A, Någren K, Rinne JO, Pohjalainen $\mathrm{T}$, Hietala J. 2009. C957T polymorphism of dopamine D2 receptor gene affects striatal DRD2 in vivo availability by changing the receptor affinity. Synapse. 63:907-912.

Hirvonen MM, Nagren K, Rinne JO, Pesonen U, Vahlberg T, Hagelberg N, Hietala J. 2010. COMT Val158Met genotype does not alter cortical or striatal dopamine D2 receptor availability in vivo. Molecular Imag Biol. 12:192-197.

Hoaglin DC, Iglewicz B. 1987. Fine-tuning some resistant rules for outlier labeling. J Am Stat Assoc. 82:1147-1149.

Ito $\mathrm{H}$, Kodaka F, Takahashi H, Takano H, Arakawa R, Shimada $\mathrm{H}$, Suhara T. 2011. Relation between presynaptic and postsynaptic dopaminergic functions measured by positron emission tomography:implication of dopaminergic tone. J Neurosci. 31:7886-7890.

Jacobs E, D'Esposito M. 2011. Estrogen shapes dopaminedependent cognitive processes: implications for women's health. J Neurosci. 31:5286-5293.

Juarez EJ, Castrellon JJ, Green MA, Crawford JL, Seaman KL, Smith CT, Dang LC, Matuskey D, Morris ED, Cowan RL et al. 2018. Reproducibility of the correlative triad among aging, dopamine receptor availability, and cognition. bioRxiv 494765.

Kaasinen S, Routtinen HM, Någren K, Lehikoinen P, Oikonen V, Rinne JO. 2000. Upregulation of putaminal dopamine D2 receptors in early Parkinson's disease: a comparative PET study with [11C] raclopride and [11C]N-methylspiperone. J Nucl Med. 41:65-70.

Kapur S, Craik FI, Jones C, Brown GM, Houle S, Tulving E. 1995. Functional role of the prefrontal cortex in retrieval of memories: a PET study. Neuroreport. 6:1880-1884.

Karalija N, Papenberg G, Wåhlin A, Johansson J, Andersson $\mathrm{M}$, Axelsson J, Riklund $\mathrm{K}$, Lövdén $\mathrm{M}$, Lindenberger $\mathrm{U}$, Bäckman L et al. 2019. C957T-mediated variation in ligand affinity affects the association between 11C-raclopride binding potential and cognition. J Cogn Neurosci. 31: 314-325.

Karrer TM, Josef AK, Mata R, Morris ED, Samanez-Larkin GR. 2017. Reduced dopamine receptors and transporters but not synthesis capacity in normal aging adults: a meta-analysis. Neurobiol Aging. 57:36-46.

Karoum F, Chrapusta SJ, Egan MF. 1994. 3-methoxytyramine is the major metabolite of released dopamine in the rat frontal cortex: reassessment of the effects of antipsychotics on the dynamics of dopamine release and metabolism in the frontal cortex, nucleus accumbens, and striatum by a simple two pool model. J Neurochem. 63:972-979.

Kesby JP, Eyles DW, McGrath JJ, Scott JG. 2018. Dopamine, psychosis and schizophrenia: the widening gap between basic and clinical neuroscience. Transl Psychiatry. 8:30.

Kolomiets B, Marzo A, Caboche J, Vanhoutte P, Otani S. 2009. Background dopamine concentration dependently facilitates long-term potentiation in rat prefrontal cortex through postsynaptic activation of extracellular signal-regulated kinases. Cereb Cortex. 19:2708-2718. 
Kimberg DY, Esposito MD, Farah MJ. 1997. Effects of bromocriptine on human subjects depend on working memory capacity. Neuroreport. 8:3581-3585.

Krug A, Dietsche B, Zöllner R, Yüksel D, Nöthen MM, Forstner AJ, Rietschel M, Dannlowski U, Baune BT, Maier R et al. 2018. Polygenic risk for schizophrenia affects working memory and its neural correlates in healthy subjects. Schizophr Res.

Laruelle M. 2000. Imaging synaptic neurotransmission with in vivo binding competition techniques: a critical review.J Cereb Blood Flow Metab. 20:423-451.

Laukka EJ, Lövdén M, Herlitz A, Karlsson S, Ferencz B, Pantzar A, Keller K, Graff C, Fratiglioni L, Bäckman L. 2013. Genetic effects on old-age cognitive functioning: a population-based study. Psychol Aging. 28:262-274.

Li SC, Lindenberger U, Sikstrom S. 2001. Aging cognition: from neuromodulation to representation. Trends Cogn Sci. 5:479-486.

Li SC, Sikström S. 2002. Integrative neurocomputational perspectives on cognitive aging, neuromodulation, and representation. Neurosci Biobehav Rev. 26:795-808.

Li SC, Papenberg G, Nagel IE, Preuschhof C, Schröder J, Nietfeld W, Bertram L, Heekeren HR, Lindenberger U, Bäckman L. 2013. Aging magnifies the effects of dopamine transporter and D2 receptor genes on backward serial memory. Neurobiol Aging. 34:358.e1-e10.

Liggins JTP. 2009. The roles of dopamine D1 and D2 receptors in working memory function. MSURJ. 4:39-45.

Logan J, Fowler JS, Volkow ND, Wang GJ, Ding YS, Alexoff DL. 1996. Distribution volume ratios without blood sampling from graphical analysis of PET data. J Cereb Blood Flow Metab. 16:834-840.

Lotta T, Vidgren J, Tilgmann C, Ulmanen I, Melen K, Julkunen I, Taskinen J. 1995. Kinetics of human soluble and membranebound catechol O-methyltransferase: a revised mechanism and description of the thermolabile variant of the enzyme. Biochemistry. 34:4202-4210.

Lövdén M, Karalija N, Andersson M, Wåhlin A, Axelsson J, Köhncke Y, Jonasson LS et al. 2018. Latent-profile analysis reveals behavioral and brain correlates of dopamine-cognition associations. Cereb Cortex. 28:3894-3907.

Matsumoto M, Shannon C, Weickert S, Akil M, Lipska BKK, Hyde M, Herman M, Kleinman JE, Weinberger DR. 2003. Catechol Omethyltransferase mRNA expression in human and rat brain: evidence for a role in cortical neuronal function. Neuroscience. 116:127-137.

Mottola DM, Kilts JD, Lewis MM, Connery HS, Walker QD, Jones SR, Booth RG et al. 2002. Functional selectivity of dopamine receptor agonists. I. Selective activation of postsynaptic dopamine D 2 receptors linked to adenylate cyclase. J Pharmacol Exp Ther. 301:1166-1178.

Müller NCJ, Konrad BN, Kohn N, Muñoz-López M, Czisch M, Fernández G, Dresler M. 2018. Hippocampal-caudate nucleus interactions support exceptional memory performance. Brain Struct Func. 223:1379-1389.

Nevalainen N, Riklund K, Andersson M, Axelsson J, Ögren M, Lövdén $M$, Lindenberger $U$, Bäckman L, Nyberg L. 2015. COBRA: a prospective multimodal imaging study of dopamine, brain structure and function, and cognition. Brain Res. 1612:83-103.

Nickl-Jockschat T, Janouschek H, Eickhoff SB, Eickhoff CR. 2015. Lack of meta-analytic evidence for an impact of COMT Val158Met genotype on brain activation during working memory tasks. Biol Psychiatry. 78:e43-e46.
Nyberg L, Andersson M, Kauppi K, Lundquist A, Persson J, Pudas S, Nilsson L-G. 2014. Age-related and genetic modulation of frontal cortex efficiency. J Cogn Neurosci. 26:746-754.

Nyberg L, Karalija N, Salami A, Andersson M, Wåhlin A, Kaboovand N, Köhncke $Y$ et al. 2016. Dopamine D2 receptor availability is linked to hippocampal-caudate functional connectivity and episodic memory. Proc Natl Acad Sci U S A. 113:7918-7923.

Nyberg L, Lövdén M, Riklund K, Lindenberger U, Bäckman L. 2012. Memory aging and brain maintenance. Trends Cogn Sci. 16:292-305.

O’Reilly RC. 2006. Biologically based computational models of high-level cognition. Science. 314:91-94.

Papenberg G, Bäckman L, Nagel IE, Nietfeld W, Schröder J, Bertram L, Heekeren HR, Lindenberger U, Li S-C. 2014. COMT polymorphism and memory dedifferentiation in old age. Psychol Aging. 29:374-383.

Puig MV, Antzoulatos EG, Miller EK. 2014. Prefrontal dopamine in associative learning and memory. Neuroscience. 282:217-229.

Rieckmann A, Karlsson S, Karlsson P, Brehmer Y, Fischer H, Farde L, Nyberg L, Bäckman L. 2011. Dopamine D1 receptor associations within and between dopaminergic pathways in younger and elderly adults: links to cognitive performance. Cereb Cortex. 21:2023-2032.

Salami A, Rieckmann A, Karalija N, Avelar-Pereira B, Andersson M, Wåhlin A, Papenberg G, Garrett DD, Riklund K, Lövdén M et al. 2018. Neurocognitive profiles of older adults with workingmemory dysfunction. Cereb Cortex. 28:2525-2539.

Sawaguchi T. 2001. The effects of dopamine and its antagonists on directional delay-period activity of prefrontal neurons in monkeys during an cculomotor delayed-response task. Neurosci Res. 41:115-128.

Shallice T, Fletcher P, Frith CD, Grasby P, Frackowiak RS, Dolan RJ. 1994. Brain regions associated with acquisition and retrieval of verbal episodic memory. Nature. 368:633-635.

Shafiei G, Zeighami Y, Clark CA, Coull JT, Nagano-Saito A, Leyton M, Dagher A, Bratislav MB. 2019. Dopamine signaling modulates the stability and integration of intrinsic brain networks. Cereb Cortex. 29:397-409.

Slifstein M, Kolachana B, Simpson EH, Tabares P, Cheng B, Duvall M, Frankle WG, Weinberger DR, Laruelle M, Abi-Dargham A. 2008. COMT genotype predicts cortical-limbic D1 receptor availability measured with [11C]NNC112 and PET. Mol Psychiatry. 13:821-827.

Tabachnick BG, Fidell LS. 2006. Using multivariate statistics. 5th ed. Needham Heights (MA): Allyn \& Bacon, Inc.

Takahashi H, Kato M, Takano H, Arakawa R, Okumura M, Otsuka T, Kodaka F, Hayashi M, Okubo Y, Ito H et al. 2008. Differential contributions of prefrontal and hippocampal dopamine $\mathrm{D}(1)$ and $D(2)$ receptors in human cognitive functions. J Neurosci. 28:12032-12038.

Thobois S, Vingerhoets F, Fraix V, Xie-Brustolin J, Mollion H, Costes N, Mertens P, Benabid AL, Pollak P, Broussolle E et al. 2004. Role of dopaminergic treatment in dopamine receptor down-regulation in advanced Parkinson disease: a positron emission tomographic study. Arch Neurol. 61:1705-1709.

Vander Weele CM, Siciliano CA, Matthews GA, Namburi P, Izadmehr EM, Espinel IC, Nieh EH, Schut EHS, Padilla-Coreano N, Burgos-Robles A et al. 2018. Dopamine enhances signal-tonoise ratio in cortical-brainstem encoding of aversive stimuli. Nature. 563:397-401.

Vincent JL, Kahn I, Snyder AZ, Raichle ME, Buckner R. 2008. Evidence for a frontoparietal control system revealed by 
intrinsic functional connectivity. J Neurophysiol 100 (6): 3328-42. doi:10.1152/jn.90355.2008.

Volkow ND, Wang GJ, Fowler JS, Logan J, Hitzemann R, Ding YS, Pappas N, Shea C, Piscani K. 1996. Decreases in dopamine receptors but not in dopamine transporters in alcoholics. Alcohol Clin Exp Res. 20:1594-1598.

Wang M, Vijayraghavan S, Goldman-Rakic PS. 2004. Selective D2 receptor actions on working memory. Science. 303: 853-857.

Wang Y, Li J, Chen C, Chen C, Zhu B, Moysis RK, Lei C et al. 2013. COMT rs4680 met is not always the 'smart allele': Val allele is associated with better working memory and larger hippocampal volume in healthy Chinese. Genes Brain Behav. 12:323-329.

Wardle MC, Hart AB, Palmer AA, de Wit H. 2013. Does COMT genotype influence the effects of $D$-amphetamine on executive functioning? Genes Brain Behav. 12:13-20.
Williams G, Goldman-Rakic PS. 1995. Modulation of memory fields by dopamine D1 receptors in prefrontal cortex. Nature. 376:572-575.

Wimber M, Schott BH, Wendler F, Seidenbecher CI, Behnisch G, Macharadze T, Bäuml K-H T, Richardson-Klavehn A. 2011. Prefrontal dopamine and the dynamic control of human long-term memory. Transl Psychiatry. 1:e15.

Winterer G, Weinberger DR. 2004. Genes, dopamine and cortical signal-to-noise ratio in schizophrenia. Trends Neurosci. 27:683-690.

Witte VA, Floel A. 2012. Effects of COMT polymorphisms on brain function and behavior in health and disease. Brain Res Bull. 88:418-428.

Yavich L, Forsberg MM, Karayiorgou M, Gogos JA, Mannisto PT. 2007. Site-specific role of catechol-O-methyltransferase in dopamine overflow within prefrontal cortex and dorsal striatum. J Neurosci. 27:10196-10209.

\section{Appendix}

Table A1 Binding potential (BP $\mathrm{ND}_{\mathrm{N}}$ ) in the four prefrontal regions-of-interest across COMT groups.

\begin{tabular}{lccccc}
\hline & $\begin{array}{c}\text { Met/Met } \\
\mathrm{n}=52\end{array}$ & $\begin{array}{c}\text { Val/Met } \\
\mathrm{n}=85\end{array}$ & $\begin{array}{c}\text { Val/Val } \\
\mathrm{n}=38\end{array}$ & $\begin{array}{c}\text { Met/Met vs. } \\
\text { Val/Val }\end{array}$ & $\begin{array}{c}\text { Met/Met vs. Val/Val } \\
\text { (adjusted for sex) }\end{array}$ \\
\hline BA9 left & Mean (SD) & Mean (SD) & Mean (SD) & t-value (p-value) & F-value (p-value) \\
BA9 right & $.0864(.0451)$ & $.0934(.0429)^{\mathrm{a}}$ & $.1020(.0469)$ & $1.60(.11)$ & $2.0(.16)$ \\
BA46 left & $.1060(.0434)$ & $.1081(.0484)$ & $.1216(.0495)$ & $1.59(.12)$ & $1.6(.22)$ \\
BA46 right & $.1616(.0480)^{\mathrm{a}}$ & $.1685(.0434)$ & $.1776(.0399)$ & $1.68(.10)$ & $2.1(.16)$ \\
dlPFC & $.1880(.0419)^{\mathrm{a}}$ & $.1869(.0372)$ & $.1980(.0387)$ & $1.15(.25)$ & $.94(.34)$ \\
& 48.8434 & 49.6933 & 52.4101 & $1.65(.10)$ & $1.9(.17)$ \\
\hline
\end{tabular}

BPND = binding potential; BA = Brodmann area dlPFC = dorsolateral prefrontal cortex; ANCOVA = analysis of covariance with sex as covariate; left = left hemisphere right = right hemisphere. dlPFC is shown in t-score metric and based on an average of BA9 (left and right) and BA46 (left and right).

a one univariate outlier was excluded 